\title{
Colour vision and dark adaptation in high myopia without central retinal degeneration
}

\author{
Maija Mäntyjärvi, Kaija Tuppurainen
}

\begin{abstract}
Colour vision and dark adaptation of 36 high myopes (68 eyes) without degenerative fundus changes were studied with the standard pseudoisochromatic plates part 2, Farnsworth-Munsell 100 hue (FM 100) test, Nagel anomaloscope, colour vision meter 712-anomaloscope, and GoldmannWeekers adaptometer. The ages of the myopes ranged from 20 to 49 years, the visual acuity from $6 / 12$ to $6 / 6$, and the refractions from $-6 \cdot 0$ to $-20 \cdot 0 \mathrm{D}$. All the colour vision tests and dark adaptation examination gave normal results. However, the error scores of the myopes in (blue) box III of the FM 100 test were significantly higher than those of the controls matched for age. In dark adaptation, the rod thresholds of the myopes were significantly higher than in the controls. The stretching of the posterior pole of the eye might explain this minimal impairment of the photoreceptor layer of the retina without any visible degenerative changes in the fundus.

(Br f Ophthalmol 1995; 79: 105-108)
\end{abstract}

Current interest in psychophysical studies of eyes with high myopia has lessened compared with many studies which date from the last century and earlier decades of this century. In colour vision, both normal and defective colour vision, mostly with a tritan defect, have been found in high myopia. ${ }^{1}$ François and Verriest $^{2}$ reported in their series of 13 high myopes ( 15 eyes) six eyes with a tritan defect, two eyes with normal colour vision, and six eyes where the red-green anomalous quotient (AQ) had been shifted towards red (pseudoprotanomaly); one eye had a congenital red (protan) defect. In the study of $\mathrm{Cox}^{3}$ all six patients passed the Ishihara plate test, one had a slight tritan defect in the Hardy-Rand-Rittler (HRR) plate test, and two had a tritan defect in the Farnsworth-Munsell 100 hue (FM 100) test; the four patients who passed the FM 100 test had very poor normal discrimination of all colours, but no definite defect. Blach ${ }^{4}$ studied 52 patients with HRR plates and found 30 with normal colour vision, nine with a blue-yellow defect, nine with a blue-yellow and red-green defect, two with a red-green defect, and a total colour vision defect in two patients. Klein and
Curtin $^{5}$ studied patients with high myopia, who had laquer crack lesions and other degenerative changes in the fundus: HRR plates gave normal results in nine of 11 eyes.

The changes in the dark adaptation of high myopes have been found to follow the degree of the myopia, but also normal adaptation has been reported. ${ }^{6}$ Blach $^{4}$ found 11 patients with normal and one with abnormal dark adaptation. Bränd'stedt ${ }^{7}$ observed significant elevation in the rod threshold of 1363 high myopic eyes compared with that of the control group. This elevation was also related to the degree of the myopic refraction. Matthey ${ }^{8}$ studied 22 children with high myopia and found that the thresholds were abnormally elevated at the beginning of the dark adaptation curve indicating cone dysfunction. Jayle and Ourgaud, referred to by Jayle et $a l^{6}$ in their study of 77 high myopic eyes, found that above the myopic refraction values of $-15 \mathrm{D}$, a moderate but clear deterioration of the mean final threshold could be observed. With the refractions less myopic than $-15 \mathrm{D}$, the mean thresholds were at the border of the upper margin of normal.

As both high myopes without fundus changes and with degenerative macular and peripheral changes have been included in all these earlier studies, it is difficult to interpret the role of the degenerative changes in the colour vision or dark adaptation defects.

The purpose of the present study was to analyse colour vision and dark adaptation in high myopes with no fundus changes to see if any abnormalities were present in advance of possible degenerative changes due to high myopia.

\section{Subjects and methods}

Fifty people with high myopia were invited to the study from the files of the ophthalmological department in the University Hospital of Kuopio. All those living in the district of the University Hospital of Kuopio and having a myopic refraction error (at least in one eye and one axis) of $-10.0 \mathrm{D}$ or more, hyperopic error of $+6.0 \mathrm{D}$ or more, or an astigmatic error of 4.0 D or more can have their spectacles free once in 5 years provided that the spectacles are made by the optician at the ophthalmological department. Therefore, people with high myopia without any retinal changes would be expected in this study group. Twelve of the 
Table 1 Farnsworth-Munsell 100 hue test (FM 100) error scores (in square roots) in different age groups for high myopes and controls

\begin{tabular}{|c|c|c|c|c|c|c|}
\hline \multirow[b]{4}{*}{ Test } & \multicolumn{6}{|c|}{ Age groups (years) } \\
\hline & \multirow{2}{*}{\multicolumn{2}{|c|}{$\frac{20-29}{\text { No of eyes }}$}} & \multirow{2}{*}{\multicolumn{2}{|c|}{$\frac{30-39}{\text { No of eyes }}$}} & \multirow{2}{*}{\multicolumn{2}{|c|}{$\frac{40-49}{\text { No of eyes }}$}} \\
\hline & & & & & & \\
\hline & 13 (myopes) & 30 (controls) & 13 (myopes) & 21 (controls) & 10 (myopes) & 34 (controls) \\
\hline $\begin{array}{l}\text { FM } 100 \\
\text { Mean (SD) }\end{array}$ & $8 \cdot 1(2 \cdot 2)$ & $7 \cdot 5(2 \cdot 5)$ & $8 \cdot 4(2 \cdot 8)$ & $7 \cdot 7(3 \cdot 1)$ & $9 \cdot 6(2 \cdot 6)$ & $9 \cdot 5(2 \cdot 6)$ \\
\hline $\begin{array}{l}\text { Box I } \\
\text { Mean (SD) } \\
\text { Box II }\end{array}$ & $1.9(2 \cdot 1)$ & $1.6(1 \cdot 3)$ & $2 \cdot 8(1 \cdot 7)$ & $1.8(1.6)$ & $3 \cdot 1(2 \cdot 3)$ & $2 \cdot 7(1 \cdot 6)$ \\
\hline $\begin{array}{l}\text { Mean (SD) } \\
\text { Box III }\end{array}$ & $4.0(1 \cdot 2)$ & $3.6(1 \cdot 7)$ & $4 \cdot 1(1 \cdot 7)$ & $3 \cdot 7(2 \cdot 2)$ & $4 \cdot 7(1 \cdot 2)$ & $4.9(1.3)$ \\
\hline $\begin{array}{l}\text { Mean (SD) } \\
\text { Box IV }\end{array}$ & $5.3(0.8)^{\star}$ & $3.8(1.4)^{\star}$ & $5.0(1 \cdot 6) t$ & $3.7(1 \cdot 7) \dagger$ & $5 \cdot 8(1 \cdot 6) \ddagger$ & $4 \cdot 7(1 \cdot 2) \ddagger$ \\
\hline Mean (SD) & $3.6(1.8)$ & $3 \cdot 6(2 \cdot 0)$ & $4 \cdot 2(1.9)$ & $4 \cdot 2(1.9)$ & $4 \cdot 7(1 \cdot 3)$ & $5 \cdot 1(1 \cdot 8)$ \\
\hline
\end{tabular}

$\star$ Difference significant, $p=0.0005$; †difference significant, $p=0.03$; ‡difference significant, $\mathrm{p}=0.02$.

invited people with myopia did not come to the eye examination, two were excluded because of degenerative changes in the fundus. This left 36 people with high myopia (68 eyes), 30 women and six men, in the study group. Their ages ranged from 20 to 49 years (mean 34.0 (SD 7.5)), the visual acuities from $6 / 12$ to $6 / 6$ (mean 6/6.9 (1.4)), and the refractions (in spherical equivalents) from $-6.0 \mathrm{D}$ to $-20.0 \mathrm{D}$ (mean $-11 \cdot 1(2 \cdot 7)$ ). The three eyes with a visual acuity of $6 / 12$ were amblyopic eyes with no other pathology. The individuals in the study group had no diseases or were not taking any medications, and none of them had been born prematurely. The myopic refraction had been first noticed at the age of 4-12 years and progressed mostly in the school years; so, all of them most probably had axial myopia (oculometric measurements were not available). They had no lens opacities, keratoconus, or central fundus changes. Temporal myopic crescent was found in nine myopes (16 eyes). Seven myopes (13 eyes) had slight lattice degeneration in a small area in the peripheral retina and, after the eye examinations, laser treatment was recommended for them.

The eye examination consisted of testing the visual acuity, refraction, phorias and tropias, as well as biomicroscopy, ophthalmoscopy (fundus examination was also performed with the Goldmann three mirror lens), and retinoscopy with the aid of tropicamide $0.5 \%+$ phenylephrine $5 \%$ drops. The tension was measured with the Goldmann applanation tonometer.

During the colour vision and dark adaptation examinations, the individuals wore the correction of the refraction with a near addition when needed. Results from the right eye (if only one eye was examined, the left eye was accepted) of the myopes were used in the calculations (36 eyes). Colour vision was examined monocularly with the following tests: the standard pseudoisochromatic plates part 2 (SPP 2) ${ }^{9}$; the Farnsworth-Munsell 100 hue test (FM 100). ${ }^{10}$ The error scores were calculated as square roots, ${ }^{11}$ the axis according to Smith et $a l^{12}$ and the results were drawn according to Kinnear. ${ }^{11}$ The results have also been calculated separately in all four boxes of the test. Scores in the different age groups (20-29 years (13 myopes), 30-39 years (13 myopes), and 40-49 years (10 myopes)) have been calculated separately; the error scores change with the age. ${ }^{13}$ Illumination was provided by the Macbeth Easel lamp.

The Nagel anomaloscope (Schmidt \& Haensch, Berlin, Germany) was used for detecting red and green colour vision defects. The examination is based on the Rayleigh equation: monochromatic green and red are mixed and the mixture is compared with monochromatic yellow. Examination with the anomaloscope was made according to the principles described by Linksz, referred to by Birch et al. ${ }^{14}$ Anomalous quotients (AQ) from 0.7 (towards red) to 1.3 (towards green) and matching ranges (MR) from 0 to 7 scale units were considered normal. ${ }^{14}$ The normal mean mid matching point (MMP), on which the calculation of the $A Q$ is based, does not change with age before about 60 years, ${ }^{1516}$ so, all results in the present study can be combined.

The colour vision meter 712 (CVM; Interzeag, Schlieren, Switzerland), where red, green (Rayleigh equation) and blue (Moreland equation) colour vision can be examined was also used, ${ }^{17}$ but in this study, only the blue equation of the anomalometer was used. In the equation, blue and green spectral colours are mixed in different proportions and compared with cyan blue colour. The AQs from 0.7 (towards green) to 1.4 (towards blue) and matching ranges from 0 to 12 scale units were considered normal. The mean MMP changes in the blue equation in different age groups. ${ }^{15}$ This has been taken into consideration when the AQs were calculated. (The normal mean MMP values for each age group have been defined in controls.) The results of the blue equation can also be expressed together. Only 14 myopes were examined with the CVM, because the equipment was only available once the study had begun. Twenty minutes was required to complete the colour vision tests in one eye.

The dark adaptation examination was done monocularly with the Goldmann-Weekers adaptometer (Haag-Streit, Bern, Switzerland) according to the instructions in method I: the absolute threshold. The area of fixation was a disc of $11^{\circ}$ during the first 8 minutes of the test (until the cone-rod break time), and after that, the fixation point was changed to $3 \mathrm{~cm}$ up from the upper border of the disc. Thus, the area of stimulation was from $5^{\circ}$ to $16^{\circ}$ during the remaining 27 minutes of the examination. The stimulating light was white with the luminance of $1 \mathrm{~cd} / \mathrm{m}^{2}$ at the brightest point of the test. There are no significant differences between the age groups in normal thresholds and times until 50 years in normal eyes. The results can therefore be combined. Thirty five minutes was required to complete the dark adaptation test in one eye.

There were 85 controls ( 30 in the 20 years age group, 21 in the 30 year age group, and 34 in the $\mathbf{4 0}$ years age group) in the FM 100 test, 38 persons in the dark adaptation test, 37 persons in the Nagel anomaloscope testing, and 29 persons in the CVM testing. The right eye of the controls was used in the calculations. 


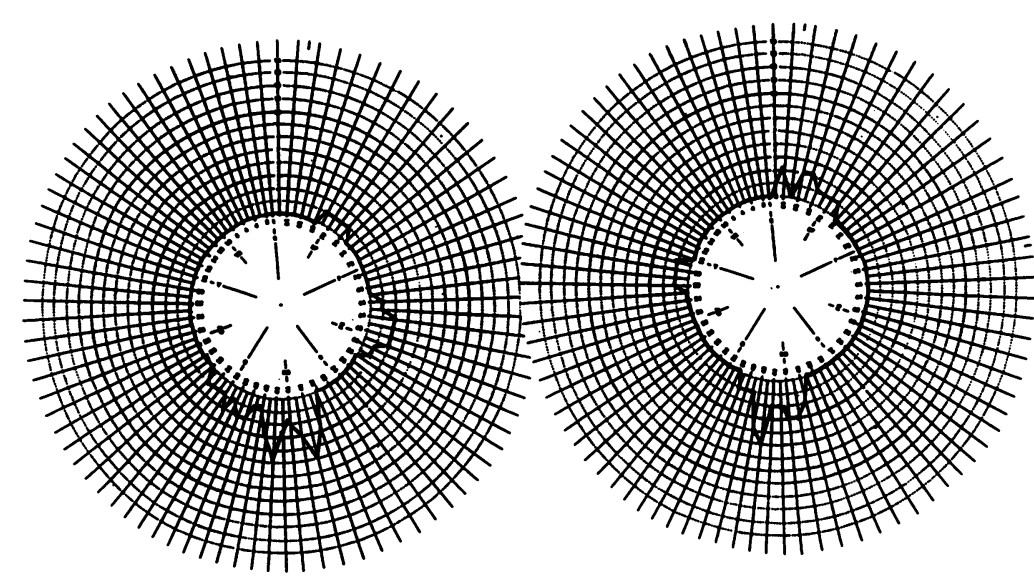

Figure 1 FM 100 test results in the right eye of a 20-year-old myopic $(-11 \cdot 5 \mathrm{D})$ woman (left) and a 32-year-old myopic $(-13.0 \mathrm{D})$ woman (right). Their total error scores are less than the mean normal error scores for these ages; however, a blue axis can be calculated in both. ${ }^{12}$ relevant normal age ranges. Ten of the myopes (11 eyes) had a blue axis in the FM 100 test, although their error scores were well within the normal range (Fig 1). The results of the Nagel anomaloscope and CVM examinations are given in Table 2. There were no significant differences in these results between the myopes and controls. The results of the dark adaptation examination are given in Table 3 . The rod threshold of the myopes was significantly higher than that of the controls, even if they were within the normal range. In the FM 100 test a significant correlation was found only in the group of 40 to 49 year olds with regard to linear regression: the degree of the myopic refraction had a significant positive correlation with the error scores of box IV (Table 4). There was no significant correlation between the degree of the myopic refraction and anomaloscopic colour vision test results or any of the parameters in dark adaptation (Tables 5, 6).

Table 2 Nagel anomaloscope (Rayleigh equation, red-green), and colour vision meter 712 (Moreland equation, blue) test results in high myopes and controls

\begin{tabular}{|c|c|c|}
\hline & Myopes & Controls \\
\hline \multirow{3}{*}{$\begin{array}{l}\text { Rayleigh equation: } \\
\text { Anomalous quotient } \\
\text { Mean (SD) } \\
\text { Matching range } \\
\text { Mean (SD) }\end{array}$} & (No of eyes 36) & (No of eyes 37) \\
\hline & $0.99(0.17)$ & $0.97(0.07)$ \\
\hline & $1 \cdot 8(1 \cdot 1)$ & $2 \cdot 0(1 \cdot 1)$ \\
\hline \multirow{3}{*}{$\begin{array}{l}\text { Moreland equation: } \\
\text { Anomalous quotient } \\
\text { Mean (SD) } \\
\text { Matching range } \\
\text { Mean (SD) }\end{array}$} & (No of eyes 14) & (No of eyes 29) \\
\hline & $0.98(0.12)$ & $1.00(0.18)$ \\
\hline & $4.5(3.2)$ & $6.4(3.7)$ \\
\hline
\end{tabular}

The ages of the controls ranged from 20 to 49 years. The visual acuities in all eyes in the control group were $6 / 6$ or better. In our clinic, a control group has been studied for each set of equipment to establish normal values for comparison when examining clinical patients.

In the statistical evaluation, Student's $t$ test (unpaired) and linear regression were used. Because some of the groups did not show a normal distribution, all groups were also tested using the Mann-Whitney $\mathrm{U}$ test. Both the $t$ test and Mann-Whitney $U$ test gave the same results; the $\mathrm{p}$ values of the $t$ test are given in the results.

\section{Results}

The SPP2 plates were seen correctly by all the myopes. The results of the FM 100 test are given in Table 1 . The myopes had significantly higher error scores with box III (though within the normal age range), than the controls in all age groups. All the results were within the

Table 3 Dark adaptation test results in high myopes and controls

\begin{tabular}{|c|c|c|}
\hline & $\begin{array}{l}\text { Myopes } \\
\text { (No of eyes 36) }\end{array}$ & $\begin{array}{l}\text { Controls } \\
\text { (No of eyes 38) }\end{array}$ \\
\hline $\begin{array}{l}\text { Cone threshold (log units) } \\
\text { Mean (SD) }\end{array}$ & $4.30(0 \cdot 26)$ & $4.22(0 \cdot 20)$ \\
\hline $\begin{array}{l}\text { Cone time (min) } \\
\text { Mean (SD) } \\
\text { Rod threshold (log units) }\end{array}$ & $5 \cdot 8(1 \cdot 1)$ & $5.8(0.9)$ \\
\hline $\begin{array}{l}\text { Mean (SD) } \\
\text { Rod time (min) }\end{array}$ & $2.24(0.08)^{\star}$ & $2 \cdot 12(0 \cdot 16)^{\star}$ \\
\hline Mean (SD) & $27 \cdot 9(2 \cdot 3)$ & $27 \cdot 0(2 \cdot 6)$ \\
\hline
\end{tabular}

^Difference significant, $\mathrm{p}=0.0001$.

\section{Discussion}

All the people with high myopia in the present study had normal colour vision with the SPP2 plates, the FM 100 test, and the anomaloscopes.

In the past, colour vision defects in high myopes have been frequently found. ${ }^{1-5}$ In all these studies, patients both with and without degenerative changes were included. Further, the state of the lens was not given except in the study of Blach. ${ }^{4}$ He reported that only about a third of the eyes with a blue defect had a clear lens. This study had high myopic eyes without degenerative central fundus changes or lens opacities which may explain why the results of colour vision tests were within normal ranges.

However, the high myopic eyes had significantly higher scores of the (blue) box III than the controls in each age group. The same result was found in the study of Koike and Tokoro ${ }^{18}$. in the spectral sensitivity test, the green and red sensitivities of high myopes without degenerative fundus changes were almost the same as in the control group, but their sensitivity to blue colour was reduced, Comberg ${ }^{19}$ has also observed reduced blue colour sense in myopic eyes.

The short wavelength sensitive blue cones (s-cones) comprise only $10 \%$ of the human retinal cones and seem to be more vulnerable in many retinal diseases than the long wavelength red cones (l-cones) or middle wavelength green cones ( $m$-cones). The distribution of blue cones in the primate retina has been shown to comprise $3 \%$ at the area from fovea to the eccentricity of $0.5^{\circ}, 20 \%$ at the eccentricities from $0.5^{\circ}$ to $1^{\circ}$, and $13 \%$ at the eccentricities from $5^{\circ}$ to $40^{\circ} .2021$ Could the stretching of the posterior pole of the fundus in the high myopes cause reduced blue colour discrimination? Could these fewer in number and vulnerable blue cones be the first to be affected in high myopia too, without any visible degenerative fundus changes? It has been reported that in high myopia, the degenerative changes in the retinal layers seem to stop at the inner nuclear layer, ${ }^{22}$ thus leaving the further 
Table 4 Correlation between the Farnsworth-Munsell 100 hue test (FM 100) error scores (right eye) and the degree of the myopic refraction in different age groups by linear regression

\begin{tabular}{|c|c|c|c|c|c|c|}
\hline \multirow[b]{2}{*}{ Test } & \multicolumn{2}{|c|}{ 20-29 Years (13 eyes) } & \multicolumn{2}{|c|}{ 30-39 Years (13 eyes) } & \multicolumn{2}{|c|}{ 40-49 Years ( 10 eyes) } \\
\hline & $\begin{array}{l}\text { Correlation } \\
\text { coefficient }\end{array}$ & p Value & $\begin{array}{l}\text { Correlation } \\
\text { coefficient }\end{array}$ & p Value & $\begin{array}{l}\text { Correlation } \\
\text { coefficient }\end{array}$ & p Value \\
\hline $\begin{array}{l}\text { FM } 100 \\
\text { Box I } \\
\text { Box II } \\
\text { Box III } \\
\text { Box IV }\end{array}$ & $\begin{array}{l}0.19 \\
0 \cdot 11 \\
0 \cdot 26 \\
0 \cdot 25 \\
0 \cdot 21\end{array}$ & $\begin{array}{l}0.52 \\
0.71 \\
0.39 \\
0.42 \\
0.50\end{array}$ & $\begin{array}{r}-0.09 \\
-0.31 \\
0.09 \\
-0.13 \\
0.06\end{array}$ & $\begin{array}{l}0.78 \\
0.30 \\
0 \cdot 77 \\
0.68 \\
0.85\end{array}$ & $\begin{array}{l}0.39 \\
0.43 \\
0.02 \\
0 \cdot 28 \\
0.68\end{array}$ & $\begin{array}{l}0.27 \\
0.22 \\
0.95 \\
0.43 \\
0.03^{\star}\end{array}$ \\
\hline
\end{tabular}

${ }^{\star}$ Correlation significant, the equation: $y=0 \cdot 34 x-0.055$.

inner pathways of colour vision and light sense in the retina untouched.

In linear regression, no significant correlation was found between the degree of myopic refraction and colour vision test results except in the FM 100 test in the 40 to 49 -year-old myopes. They had a significant correlation in scores in box IV (blue-purple-red box) also suggesting deterioration in bluish colour discrimination in higher myopic refractions in this age group. Koike and Tokoro, ${ }^{18}$ could not find any correlation between the spectral sensitivity of blue cones and the degree of myopia; however, the ages of the myopes were not given.

Dark adaptation in high myopes was also within the normal ranges in the retinal area from $0^{\circ}$ to $16^{\circ}$. Linear regression did not show any correlation between the dark adaptation test results and the degree of myopic refraction; however, in the mean rod threshold, there was a significant difference compared with the controls. The thresholds of the myopes seemed to be mostly at the upper border of the normal. In earlier studies both normal and defective dark adaptation have been found. ${ }^{4-8}$ The stimulation area was reported in only one study $^{8}$ and it was very near that of the present study, from $0^{\circ}$ to $10^{\circ}$. Again, in all these studies, high myopes both with and without degenerative fundus changes were included and so they cannot be compared with the

Table 5 Correlation between the Nagel anomaloscope (Rayleigh equation, red-green) test results (36 eyes), colour vision meter 712 (Moreland equation, blue) test results (14 eyes), and the degree of the myopic refraction by linear regression

\begin{tabular}{lrl}
\hline & Correlation coefficient & $p$ Value \\
\hline Rayleigh equation: & & \\
Anomalous quotient & -0.08 & 0.65 \\
Matching range & 0.08 & 0.66 \\
Moreland equation: & & \\
Anomalous quotient & -0.18 & 0.55 \\
Matching range & 0.26 & 0.37 \\
\hline
\end{tabular}

Table 6 Correlation between the dark adaptation test results and the degree of the myopic refraction (36 eyes) by linear regression

\begin{tabular}{lcc}
\hline & Correlation coefficient & $p$ Value \\
\hline Cone threshold & $0 \cdot 15$ & 0.38 \\
Cone time & $0 \cdot 22$ & $0 \cdot 20$ \\
Rod threshold & -0.03 & 0.88 \\
Rod time & -0.05 & 0.75 \\
\hline
\end{tabular}

present study. Only Jayle and Ourgaud, referred to by Jayle et $a l^{6}$ reported that the mean final threshold of 39 eyes with normal fundi was near the upper border of the normal, as was found in the present study.

In conclusion, colour vision and dark adaptation were within normal ranges in high myopic eyes without degenerative central fundus changes. However, blue colour discrimination was significantly worse and the level of the rod threshold significantly higher in high myopic eyes than in normal eyes. The stretching of the posterior pole in high myopic eyes might explain this minimal impairment of the photoreceptor layer of the retina.

This study was supported by the grants from Paolo Foundation, Helsinki, Finland and the Finnish Eye Foundation, Helsinki, Finland.

1 Curtin BJ. The myopias. New York: Harper \& Row, 1985 353-4.

2 François J, Verriest G. Les dyschromatopsies acquises. Ann Oculist (Paris) 1957; 190: 812-59.

3 Cox J. Colour vision defects acquired in diseases of the eye. $\mathrm{Br} \mathcal{F}$ Physiol Opt 1960; 18: 3-32.

4 Blach RK. The nature of degenerative myopia. A clinicopathological study. Thesis. University of Cambridge, 1964

5 Klein RM, Curtin BJ. Laquer crack lesions in pathologic myopia. Am f Ophthalmol 1975; 79: 386-92.

6 Jayle GE, Ourgaud AG, Baisinger LF, Holmes WJ. Night vision. Springfield, IL: Charles C Thomas, 1959: 274-80.

7 Brändstedt G. Untersuchungen über Minimum perceptile und Distinktionsvermögen des Auges. Besonders hinsichtlich ihres Verhaltens bei Myopie. Acta Ophthalmol 1935; 13 (suppl): 5-7.

8 Matthey G. Eine 'Standardkurve' der Dunkeladaptation für klinische Untersuchungen. Graefes Arch Clin Exp Ophthalmol 1932; 129: 275-98.

9 Ichikawa H, Hukami K, Tanabe S. Standard pseudoisochromatic plates, part 2. Tokyo: Igaku-Shoin Ltd, 1983.

10 Farnsworth D. The Farnsworth-Munsell 100-Hue Test. Baltimore: Munsell Color Company, 1957.

11 Kinnear PR. Proposals for scoring and assessing the 100hue test. Vision Res 1970; 10: 423-33.

2 Smith VC, Pokorny J, Pass AS. Color-axis determination on the Farnsworth-Munsell 100 -hue test. Am $₹$ Ophthalmo 1985; 100: 176-82.

13 Verriest G, Van Laethem J, Uvijls A. A new assessment of the normal ranges of the Farnsworth-Munsell 100-hue test scores. Am 7 Ophthalmol 1982; 93: 635-42.

14 Birch J, Chisholm IA, Kinnear P, Pinckers AJLG, Pokorny J, Smith VC, et al. Clinical testing methods. In: Pokorny J, Smith VC, Verriest G, Pinckers AJLG, eds. Congenital and acquired colour vision defects. New York: Grune \& Stratton, acquired colour visio

15 Roth A, Pelizzone M, Sommerhalder J, Hermès D, Simona F. The two equation method: III. Results in normal subjects above 50 years of age. Correlation with lens opacity. In: Drum B, Moreland JD, Serra A, eds. Colour vision deficiencies X. Doc Ophthalmol Proc Ser, Vol 54. Dordrecht: Kluwer, 1991: 353-9.

16 Birch J, Chisholm IA, Kinnear P, Marre M, Pinckers AJLG, Pokorny J, et al. Acquired color vision defects. In: Pokorny J, Smith VC, Verriest G, Pinckers AJLG, eds. Congenital and acquired color vision defects. New York: Grune \& Stratton, 1979: 243-348.

17 Pelizzone M, Sommerhalder J, Roth A Hermès D. Automated Rayleigh and Moreland matches on a computer-controlled anomaloscope. In: Drum B, Moreland JD, Serra A, eds. Colour vision deficiencies X. Doc Ophthalmol Proc Ser, Vol 54. Dordrecht: Kluwer, 1991 151-9.

18 Koike A, Tokoro T. Spectral sensitivities in high myopic eyes. Acta Soc Ophthalmol fpn 1986; 90: 556-60.

19 Comberg. Beziehungen zwischen Störungen des Farbensinnes und Ametropien. Klin Monatsbl Augenheilkd 1941; 107: 85.

20 Marc RE, Sperling HG. Chromatic organization of primate cones. Science 1976; 196: 454-6.

21 Sperling HG, Wright AA, Mills SL. Intense spectral light induced color blindness in rhesus monkeys. In: Verriest G, ed. Colour vision deficiencies VIII. Doc Ophthalmol Proc Ger, Vol 46. Dordrecht: Martinus Nijhoff/Dr W Junk, Ser, Vol 46.

22 Duke-Elder Sir S, Abrams D. Ophthalmic optics and refraction. In: Duke-Elder S, ed. System of ophthalmology, Vol V. London: Henry Kimpton, 1970: 314-6. 